\title{
¿CONSUMO LUEGO PIENSO, O PIENSO Y LUEGO CONSUMO? CONSUMO DE MEDIOS, PREDISPOSICIÓN POLÍTICA, PERCEPCIÓN ECONÓMICA Y APROBACIÓN PRESIDENCIAL EN CHILE*
}

\author{
Media Consumption, Political Predisposition, Economic Perception \\ and Presidential Approval in Chile
}

\author{
ARTURO ARRIAGADA ILABACA \\ Universidad Diego Portales
}

PATRICIO NAVIA LUCERO

Universidad Diego Portales

MARTÍN SCHUSTER PINEDA

Universidad Diego Portales

\begin{abstract}
RESUMEN
El consumo de medios de comunicación masiva está relacionado con las predisposiciones políticas y con las percepciones económicas de las personas. Pero no es clara la dirección de causalidad. ¿Hasta qué grado los medios influyen en esas predisposiciones políticas y percepciones económicas? O bien, ¿deciden las personas qué medios consumir en función de predisposiciones y percepciones ya existentes? Utilizando datos de encuestas que abordan la aprobación presidencial y consumo de medios en Chile en 2007 y 2008, evaluamos si las predisposiciones de las personas determinan su consumo de medios o bien si el consumo de medios influye sobre las visiones políticas y percepciones económicas. Los datos son demasiado débiles para indicar una relación causal clara en alguna dirección. Pero hay evidencia de que un mayor consumo de medios está positivamente relacionado con posturas más marcadas, tanto optimistas como pesimistas, de la población. Más que ser determinante en definir percepciones, el consumo de medios parece profundizar las percepciones ya existentes en determinados grupos. Ya sea porque los chilenos consumen y luego piensan o porque piensan y luego consumen, lo que consumen profundiza lo que ya piensan así como lo que ya piensan les induce a seleccionar los medios que consumen.
\end{abstract}

Palabras clave: Consumo mediático, aprobación presidencial, determinantes de las preferencias políticas en Chile.

* Este artículo recibió financiamiento del Proyecto Fondecyt $N^{\circ} 1085243$. Agradecemos a los evaluadores anónimos por sus comentarios. Los errores y omisiones son exclusiva responsabilidad de los autores. 


\begin{abstract}
Media consumption is correlated with political predispositions and economic perceptions. But the direction of causality is not evident. To what extent do media influence political predispositions and economic perceptions? Or, do people decide the media they consume as a result of their existing political predispositions and economic perceptions? Using data from polls that measure presidential approval and media consumption in Chile in 2007 and 2008, we test to see if political predispositions determine media consumption or whether it is the other way around. The data shows correlation, but does not strongly predict causality in either direction. But more media consumption is correlated with stronger views, both optimistic and pessimistic. More than determine the level of approval, media consumption seems to strengthen already existing views. Either because Chileans consume and then think or because they think and then consume, what they consume deepens what they already think just as what they think induces them select the media they consume.
\end{abstract}

Key words: Media consumption, presidential approval, determinants of political preferences in Chile.

En Chile, tradicionalmente se asocia el periódico que leen las personas a sus posiciones políticas. Por ejemplo, se tiende a identificar a lectores de El Mercurio con posturas de derecha. Pero, ¿tienen los lectores de El Mercurio esas posturas porque leen ese periódico o más bien lo leen porque tienen posturas de derecha? De la misma forma, ¿son las percepciones económicas determinantes al momento de escoger medios o es el consumo de determinados medios el que determina las percepciones económicas de las personas? Hay consenso entre los estudiosos de la relación entre medios masivos de comunicación y las posiciones políticas y percepciones económicas de las personas respecto a que ambas cosas están relacionadas. Pero no está clara la dirección de causalidad. ¿Hasta qué grado los medios influyen en la predisposición política de los chilenos? ¿Deciden las personas qué medios consumir en función de sus predisposiciones políticas y percepciones económicas ya existentes? O bien ¿hay variables explicativas de identificación política e ideológica a largo plazo que explican tanto las percepciones políticas y el consumo de medios?

Se podría argumentar que los medios refuerzan el interés en aquellos que poseen información política y económica a la vez que fomentan el desinterés en los que no participan del proceso político ni parecen interesados en cuestiones económicas. En ese sentido, los medios intensificarían predisposiciones y percepciones iniciales. Si un $60 \%$ de los lectores de una revista de derecha se identifica como derechista, ¿la lectura de la revista causó esa condición? O bien ¿los lectores ya identificados con la derecha optan por leer esa revista? A menos que sepamos la predisposición inicial de las personas y luego midamos su predisposición posterior, no podemos distinguir esa diferencia. Pero sí podemos inferir que, en tanto los lectores de la revista no muestran diferencias en su predisposición política respecto al resto de la población con similares características ideológicas, la revista no influye en la percepción política de las personas. Por ejemplo, si la aprobación presidencial en personas de derecha que leen El Mercurio es de 30\%, mientras que entre personas de derecha que no leen El Mercurio es $50 \%$, podemos inferir que la lectura de 
El Mercurio está positivamente correlacionada con una percepción más negativa sobre el desempeño presidencial. Ahora bien, no sabemos si esa percepción más negativa lleva a la gente a leer El Mercurio o si es causada por su lectura.

De ahí que, para evaluar la relación entre predisposiciones políticas, percepciones económicas y consumo de medios, utilizamos la aprobación presidencial como variable dependiente. Si encontramos que personas con similares predisposiciones políticas y percepciones económicas pero distinto consumo de medios presentan distinta aprobación presidencial, concluimos que el consumo de medios está relacionado con la aprobación, ya sea tanto como una variable independiente que influye directamente o como una variable que influye a través de su interacción con las predisposiciones políticas y las percepciones económicas.

Por cierto, hay una multiplicidad de otras variables que influyen sobre el consumo de medios. Por ejemplo, las personas de más ingresos tienden a leer más periódicos. Aquellos con más educación tienden a leer más periódicos -y a tener más altos ingresos. Así, aún si encontramos relación entre consumo de medios y percepción política, bien pudiera explicarse por variables exógenas que dan cuenta tanto del consumo de medios como de las percepciones políticas. Por ejemplo, en 2007, las personas de más ingresos estaban más inclinadas a reprobar el desempeño de la presidenta Michelle Bachelet. Pero ya que las personas de más ingresos también tienen más probabilidades de leer periódicos, la mayor desaprobación a Bachelet entre los lectores de periódicos pudiera resultar de su condición socioeconómica y no de su consumo de medios. Así, cuando la lectura de un periódico está asociada con una visión más negativa del gobierno, eso puede ser resultado de la lectura del periódico o de la condición socioeconómica de los lectores. Adicionalmente, si suponemos que la ideología política es también exógena (causada por su origen familiar u otras variables no relacionadas con su condición socioeconómica), dicha ideología puede afectar tanto el consumo de medios como la percepción sobre la aprobación presidencial. Así, una persona de mucha educación y altos ingresos, pero que se identifica con la izquierda, pudiera aprobar con entusiasmo el desempeño presidencial pese a ser asidua lectora de diarios (por su condición económica y educacional) de derecha.

En lo que sigue, dilucidamos primero las cuestiones teóricas -con variables de largo, mediano y de corto plazo- que afectan la predisposición política de las personas y las variables de corto plazo que dan cuenta de su percepción económica. Luego, analizamos las variables que explican el consumo de medios. Posteriormente discutimos la relación entre predisposiciones políticas y consumo de medios y percepción sobre la economía y aprobación presidencial. Finalmente, a partir de datos de encuestas nacionales realizadas en 2007 y 2008, estudiamos la relación entre predisposiciones políticas, percepciones sobre la economía y consumo de medios y la aprobación presidencial. En particular, analizamos la relación entre consumo de televisión, diarios y radio y la aprobación presidencial que recibió la Presidenta Bachelet en dicha encuesta. 


\section{PREDISPOSICIONES POLÍTICAS DE LAS PERSONAS, VARIABLES DE CORTO Y LARGO PLAZO}

El origen de las percepciones políticas se asocia a variables explicativas de largo, mediano y corto plazo, y con consideraciones que incluyen evaluaciones retrospectivas y prospectivas sobre la situación económica personal y del país (voto bolsillo sociotrópico u egotrópico) (Lau and Redlawsk, 2006). Las variables de largo plazo se refieren a características heredadas que permanecen estables, incluso inmutables. Las de mediano plazo se refieren a procesos de socialización y son influidos por eventos importantes en las vidas de las personas. Finalmente, las consideraciones de corto plazo normalmente se asocian con modelos que suponen electores racionales que premian o castigan al gobierno a partir de su evaluación sobre la situación económica personal o del país. Cada uno de estos modelos explicativos entiende el papel de los medios desde ópticas distintas.

Las variables de largo plazo se asocian con el Modelo Sociológico de Columbia. Esta escuela sugiere que las percepciones políticas están asociadas a características de raza, sexo, religión, condición de clase o etnia (Lipset y Rokkan, 1967, 1990). Así, por ejemplo, la aprobación presidencial en una mujer de clase obrera y católica depende de qué tan cerca esté ideológica y socialmente del grupo al que pertenece. De la misma forma, podemos entender el consumo de medios de comunicación como resultado de variables de largo plazo. Así como las personas heredan su condición étnica o de clase, también heredan los periódicos que leen y los canales de televisión que observan. El consumo de medios estaría asociado a la posición política heredada (Lazarsfeld et al., 1944; Crewe, 1995). La influencia de ese medio sobre una persona está asociada a las motivaciones heredadas que la llevaron a elegir dicho medio.

Una lectura alternativa sobre las preferencias políticas se centra en variables de mediano plazo. Así, el Modelo de Michigan centra su atención en los procesos de socialización. Por ejemplo, independientemente de su condición de clase, una persona que asistió a una escuela laica o que ingresó a las fuerzas armadas será afectada por ese contexto -aunque el ingreso a la rama militar haya sido producto de condiciones heredadas compatibles con el Modelo Columbia- y sus predisposiciones políticas evolucionarán afectadas por el contexto (Lau y Redlawsk, 2006). Alguien que se vio expuesto a violaciones a los derechos humanos pudiera, a partir de esa experiencia, desarrollar preferencias políticas que lo induzcan a votar sistemáticamente a favor de partidos que defiendan los derechos humanos. Esta segunda lectura permite variaciones, pero no volatilidad, en las preferencias. Si bien pudieran producirse por eventos políticos importantes -como una transición a la democracia- sus efectos son duraderos y relativamente estables. Al usar este modelo para entender el consumo de medios, las diferencias con el Modelo de Columbia tienden a desaparecer. Ya sea porque son heredadas o adquiridas a través del tiempo, las preferencias respecto a los medios responden también a las preferencias políticas.

Una tercera explicación de las posiciones políticas supone que las personas son influidas por variables de corto plazo, normalmente asociadas al desempeño económico (Powell 
y Whitten, 1993; Duch y Stevenson, 2005; Kramer, 1983; Lewis-Beck y Stegmeier, 2007). Por ejemplo, los electores premian o castigan a los gobiernos dependiendo de la inflación, crecimiento, desempleo y otros indicadores económicos. El llamado voto económico, asociado con el modelo de votante racional, o Modelo Rochester, sugiere que la aprobación presidencial se asocia al desempeño económico, la inflación y el desempleo. Por cierto, las primeras referencias al voto económico aparecen en el clásico del Modelo de Michigan (Campbell et al., 1960). Uno de los capítulos de The American Voter se titula "The Economics Antecedents of Political Behaviour". Pero ya que ha sido desarrollado mucho más desde la perspectiva del votante racional -donde racionalidad se asocia con evaluación de desempeño económico- muchos distinguen entre el votante de mediano plazo (Michigan) y el votante económico de corto plazo (Rochester).

De acuerdo al Modelo Rochester, la gente vota a partir del desempeño reciente de la economía-voto retrospectivo -o de sus expectativas sobre el futuro de la economíavoto prospectivo. De cualquier forma, es el desempeño económico, una variable de corto plazo, el mejor predictor del comportamiento electoral, y presumiblemente de las posturas políticas de las personas (Fiorina, 1978, 1981; Kiewiet, 1983; Lewis-Beck, 1988; Pacek y Radcliff, 1995; Norpoth, 1996; Suzuki y Chappl, 1996; Holbrook y Garand, 1996). Podemos evaluar hasta qué grado la aprobación de un gobierno refleja percepciones sobre el desempeño económico (Lewis-Beck y Stegmaier, 2000). Kinder y Kiewiet sugieren que hay dos tipos de percepciones individuales (1981). Por un lado, están aquellos que evalúan la realidad desde una perspectiva "egotrópica", esto es, que atribuyen más valor a su realidad personal que a la situación del país. Por otro lado, están aquellas personas que utilizan una lógica "sociotrópica", donde la evaluación que realizan sobre la realidad del país es determinante. Por distintos motivos, la evaluación sociotrópica parece ser preponderante al evaluar la realidad económica (Kiewiet, 1983; Nannestad y Paldman, 1994; Álvarez y Nagler, 1995). Desde la perspectiva del Modelo Rochester, el consumo de medios no está influido por las percepciones políticas previas sino que presumiblemente se decide a partir de la información que los electores reciben de los distintos medios. Si creemos que la gente decide su voto a partir de evaluaciones del desempeño económico, entonces el consumo de medios les permite acceder a información y no responde a predisposiciones políticas previas.

Por cierto, la capacidad predictiva de estos tres modelos varía dependiendo del país y del momento histórico. Hay evidencia de que los electores son afectados por consideraciones de largo, mediano y corto plazo al momento de elegir, por lo que estas explicaciones bien pudieran ser más complementarias que excluyentes. Las encuestas de opinión nos permiten dilucidar en qué medida las variables de corto, mediano y largo plazo interactúan para influir en las percepciones políticas.

Hay distintos estudios que, utilizando variables de corto y largo plazo, con aproximaciones sociotrópicas y egotrópicas, y evaluando hipótesis sobre la votación prospectiva y retrospectiva, buscan explicar las preferencias políticas y variaciones en los niveles de aprobación presidencial (Anderson, 1995; Lewis-Beck y Paldman, 2000; Duch, 2001), y el impacto que la aprobación presidencial tiene sobre la conducta electoral 
de los votantes (Lewis-Beck, 1986; Radcliff, 1988; Przeworski, 1991, 1996; Markus, 1992; Mishler y Rose, 1994; Popkin, 1994; Echegaray, 1996; Hellwig, 2001; Rudolph y Grant, 2002).

En Chile, aunque hay trabajos recientes que usan variables de corto plazo para dar cuenta del comportamiento electoral y de los niveles de aprobación presidencial (Cerda y Vergara, 2007; Morales, 2008; Morales et al., 2008; Morales y Navia, 2008), la tradición ha sido construir explicaciones de los determinantes del voto a partir de variables de mediano y largo plazo (Valenzuela y Scully, 1997; Angell, 2003; López y Morales, 2005; Morales y Poveda, 2007). De hecho, la literatura sociológica y política supone la existencia de clivajes históricos que dan cuenta de un ordenamiento en tercios (derecha, centro e izquierda) del sistema de partidos y de las preferencias electorales de su población (Scully, 1992; Valenzuela y Valenzuela, 1976; Gil, 1969; Garretón, 1989). Así, las percepciones políticas de los chilenos estarían basadas en clivajes históricos y serían renuentes a cambiar en el tiempo. En otras palabras, Columbia y Michigan han sido mucho más utilizados en Chile que las explicaciones emanadas del Modelo Rochester.

\section{LOS MEDIOS DE COMUNICACIÓN Y LA PERCEPCIÓN POLÍTICA DE LAS PERSONAS}

Los modelos basados en variables de largo, mediano y corto plazo pudieran ser complementarios. De hecho, la dinámica de las campañas y el desarrollo político a menudo obligan a combinar los efectos de estas distintas variables para explicar el comportamiento electoral. Pero inevitablemente surge una tensión entre explicaciones que se basan en variables de corto y largo plazo para dar cuenta del comportamiento electoral y de las percepciones políticas. Esta tensión se hace evidente al evaluar la relación entre el consumo de medios y las posturas políticas. Si la gente hereda sus preferencias políticas a partir de su condición de clase o religión, entonces el consumo de medios también será heredado a partir de las mismas variables. Si un chileno 'nace' socialista, entonces tendrá mayor predisposición a leer medios que se identifican con esa postura política. En cambio, si las personas determinan sus preferencias políticas a partir de variables de corto plazo, entonces el consumo de medios influye en la forma en que las personas se informan sobre la realidad y, consecuentemente, deciden su voto. Si aceptamos que las variables de corto plazo influyen en el comportamiento de los electores y en sus percepciones políticas, el papel que juegan los medios de comunicación masiva se torna crucial al momento de explicar por qué las personas votan como lo hacen.

En las democracias, los medios de comunicación son responsables de acercar los asuntos públicos a las personas (Iyengar \& McGrady, 2007). Los gobiernos informan sus logros a través de los medios, el principal canal de información de los ciudadanos. Esa información permite a las personas evaluar el desempeño del gobierno y contribuye a influir sus decisiones al votar (Norris, 2000). Los medios a la vez fiscalizan las acciones de los gobiernos y actores políticos (Zaller, 1992; Graber, 2000; Graber, 2001; Hall Jamieson, 1996; Zaller, 1991; Flowers, Haynes y Crespin, 2003). A través de este constante informar sobre 
asuntos públicos y fiscalizar gobiernos, los medios se convierten en filtros de información política, enmarcando y distorsionando las noticias en función de sus propios intereses particulares (políticos, comerciales y editoriales) (Zaller, 1992; Navia, 2000).

Ahora bien ¿qué lleva a las personas a buscar información respecto de los asuntos públicos en los medios de comunicación? En la década de los 70 cuando la radio, la prensa escrita -y en menor medida la televisión- dominaban la producción de información y acaparaban audiencias, Katz et al. (1973) definieron la relación entre individuos y medios como un vínculo basado en necesidades, usos y gratificaciones. Las personas utilizan los medios para satisfacer esas necesidades. Las necesidades de información -y la elección de los medios como satisfactor de ellas- podrían estar determinadas tanto por herencia familiar (Modelo Columbia) como por el interés particular en saber sobre la situación política y económica del país (Modelo Michigan).

Con la abundante información política disponible y de diversidad de medios que la proveen (prensa escrita, radio, televisión e internet), los individuos tienden a utilizar criterios de selección tanto para escoger medios como para seleccionar contenidos. Las personas segmentan la oferta informativa de acuerdo a sus intereses y necesidades a través de tres mecanismos. El primero opera cuando, al elegir la información que consideran relevante, la gente refuerza sus preferencias políticas y evita aquella información que les generen inconsistencias (Iyengar y McGrady, 2007; Iyengar y Bennett, 2009). Este proceso de selección de información y refuerzo de las preferencias es consistente con el Modelo Columbia, que supone que las personas heredan percepciones políticas, y con el Modelo Michigan, que supone que las preferencias políticas se socializan a través de los años. La información de los medios intensifica esas predisposiciones políticas heredadas o adquiridas.

En un segundo mecanismo, también consistente con el Modelo Columbia pero más cercano al de Michigan, las personas buscan información sobre "asuntos públicos" que les generan interés, como el desempeño del gobierno. Por último, un tercer mecanismo de selección opera cuando las personas que tienen interés en política sintonizan con toda la información disponible y recurren a distintas fuentes, pero aquellos que presentan un menor interés no prestan atención a ningún medio ni noticia sobre esos temas (Iyengar y McGrady, 2007). Los votantes que forman su opinión a partir de información reciente -Modelo Rochester- serían más afines a este mecanismo. Es más, su voto dependería del tipo y calidad de información a la que tienen acceso.

El modelo de Recepción-Aceptación-Muestreo (RAS) de formación de la opinión pública desarrollado por Zaller (1992) permite incluir a aquellas personas que si bien no siguen con regularidad los procesos políticos a través de los medios de comunicación, sí poseen algún grado previo de información. De acuerdo a Zaller, independiente de sus niveles de atención, las personas son receptoras de flujos de información. Estos flujos son generados por políticos, gobernantes, sociedad civil, y por los medios de comunicación que filtran esos flujos de acuerdo a sus propios intereses. Las personas pueden aceptar o rechazar esos flujos de información ya sea por sus disposiciones, como la identificación política, o por sus niveles de información política, como datos fácticos de hechos políticos pasados 
(Bargsted, 2009). Al aceptar o rechazar esos flujos de información por su identificación política, izquierda o derecha, las personas estarían actuando en forma consistente con el Modelo Columbia y el Modelo Michigan. Aunque no sabemos si la elección de esos medios en su momento estuvo determinada por predisposiciones heredadas, si esos flujos de información influyen en sus preferencias electorales estarían actuando acorde al Modelo Rochester.

Si bien la información de los medios raya la cancha a las personas respecto de los asuntos públicos que les son relevantes (McCombs y Shaw, 1972), las personas también piensan sobre un asunto o hecho en particular, dependiendo de cómo se presente esa noticia (Hall Jamieson y Kohrs, 2000; Iyengar y McGrady, 2007). Al seguir a través de los medios de comunicación el desempeño de un presidente y su gobierno, las personas seleccionan la información en función de sus necesidades y establecen criterios de evaluación y atribución de responsabilidades hacia esas autoridades (Brody, 1991; Iyengar et al., 1992). El "Priming" es el proceso mediante el cual los medios influyen en los criterios que los ciudadanos consideran relevantes para evaluar a los líderes políticos. Como consecuencia de la cobertura mediática, la ciudadanía le otorga mayor importancia a un asunto público. Esto intensifica la influencia de esos hechos en la valoración de las personas hacia políticos, candidatos y otras figuras públicas (Iyengar, 1992). Por ejemplo, si durante un período gubernamental los medio dan más atención al desempleo, las personas van a tender a apoyar al político que consideren más capacitado para enfrentar ese problema.

Las personas definen criterios de evaluación de los políticos y gobiernos a través del Priming. Esto significa que la información que presentan los medios de comunicación respecto del gobierno, el presidente y la economía del país, influye en las percepciones ciudadanas. Desde las lecturas asociadas a los modelos Columbia y Michigan, el Priming simplemente refleja las predisposiciones políticas ya existentes en las personas. En cambio, desde la perspectiva del Modelo Rochester, el Priming operaría como una variable de corto plazo que afecta las evaluaciones de las personas hacia el gobierno, la economía y el desempeño del Presidente.

En este estudio incorporamos variables que nos permitan analizar los tres modelos que dan cuenta del comportamiento electoral (Columbia, Michigan y Rochester), y agregamos el consumo de medios para ver si la información que éstos presentan es una variable que determina la aprobación presidencial. A partir de los tres modelos medimos el efecto que tiene el consumo de medios sobre las percepciones políticas de las personas, específicamente sobre la aprobación presidencial. La Figura 1 muestra las posibles relaciones de causalidad entre la predisposición política de las personas, su percepción económica, el consumo de medios y la aprobación presidencial. Como mostramos más adelante, para el caso de Chile hay evidencia de causalidad sobre la aprobación presidencial pero no entre las predisposiciones políticas y económicas y el consumo de medios. Así, el consumo de medios debería o bien repercutir o bien reflejar, pero ciertamente estar correlacionado, con diferencias en los niveles de aprobación presidencial de personas que comparten otras características de identificación sociodemográfica, predisposiciones políticas y evaluación sobre la situación económica. 
Figura 1: Relaciones de causalidad entre predisposición política, percepción económica y consumo de medios sobre aprobación presidencial

\begin{tabular}{|l|l|l|}
\hline & & \\
\hline $\begin{array}{l}\text { Predisposición política } \\
\text { y otras variables } \\
\text { de largo plazo } \\
\text { (Modelos Columbia y } \\
\text { Michigan) }\end{array}$ & & Consumo de Medios \\
\hline & & $\begin{array}{l}\text { Percepción económica } \\
\text { y otras variables } \\
\text { de corto plazo } \\
\text { (Modelo Rochester) }\end{array}$ \\
\hline
\end{tabular}

Fuente: Elaboración propia.

A partir del efecto que se atribuye al consumo de medios sobre las percepciones de la gente, ya sea porque despierta predisposiciones latentes, o porque induce a formarlas, planteamos las siguientes hipótesis que buscan evaluar si hay diferencias en la aprobación presidencial en distintos grupos asociada a la intensidad de consumo de medios escritos, radio y televisión.

- Hipótesis 1: Controlando por otras variables, la aprobación presidencial entre aquellos que se informan por televisión son similares que entre aquellos que no lo hacen.

- Hipótesis 2: Controlando por otras variables, los niveles de aprobación presidencial entre aquellos que se informan por diarios son similares a los de aquellos que no lo hacen.

- Hipótesis 3: Controlando por otras variables, los niveles de aprobación presidencial entre aquellos que se informan por radio son similares que entre aquellos que no lo hacen.

\section{CONSUMO DE MEDIOS DE COMUNICACIÓN EN CHILE}

Al seleccionar información, las personas intentan satisfacer la necesidad de entendimiento de su realidad política. Ahora bien, estos mecanismos de selección presuponen ciudadanos interesados en asuntos públicos y procesos políticos. En Chile, los ciudadanos muestran desencanto ante la política y son pocos los que siguen con frecuencia diferentes fuentes de información política (Arriagada, Navia \& Schuster, 2010).

Así y todo, como muestra la Tabla 1, la televisión es el medio de comunicación que más utilizan los chilenos para informarse. Este fenómeno se ha acrecentado en los últimos años. Si en 1996 un 76,7\% utilizaba este medio, en 2005 el número de usuarios aumentó al 83,8\%. Aunque un 35\% de los hogares posee televisión por cable, la televisión abierta domina la audiencia. Un 79,1\% de los encuestados por el Consejo Nacional de Televisión en 2005 decía ver diariamente televisión abierta, mientras un 24,7\% utilizaba televisión pagada (CNTV 2005). Los canales de televisión abierta más vistos son TVN (37,5\% de las menciones), Chilevisión (22,9\%), Canal 13 (18,2\%) y Mega (12,3\%) (ICSO-UDP 
2007). El segundo medio más utilizado es la radio, aunque ha tendido a la baja en los últimos años. Si en 1996 un 13\% decía escuchar radio para informarse, en 2005 la cifra llegó al 5,9\%.

La prensa escrita figura como el tercer medio más utilizado. En 1996 un 7,3\% utilizaba los diarios para informarse. Para 2005, esa cifra cayó al 5,2\%. La televisión se consolidó como el actor más importante en el sistema de medios de comunicación del país luego de la dictadura (Tironi y Sunkel, 1993). Entre 1973 y 1990 la prensa escrita vivió una reestructuración que derivó en un duopolio de empresas periodísticas. Luego de la censura y el cierre de distintos medios escritos a causa del golpe militar de 1973, diarios afines a la dictadura como El Mercurio y La Tercera se convirtieron en los medios dominantes del período democrático actual. La estructura de la prensa escrita quedó conformada por un duopolio liderado por los consorcios Copesa y El Mercurio S.A.P. Copesa es propietario de los diarios La Tercera, La Cuarta, el gratuito La Hora, la revista semanal Qué Pasa y la quincenal Paula. El Mercurio agrupa al diario homónimo, a Las Últimas Noticias y La Segunda, además de varios periódicos regionales (Dermota, 2002; Bresnahan, 2003). De acuerdo a la Asociación Nacional de la Prensa (ANP) de promedio total de lectores en la ciudad de Santiago entre julio y septiembre de 2007, el diario más leído fue La Cuarta (524.491), seguido de Las Últimas Noticias (387.100), El Mercurio (355.720), La Tercera (329.382), La Segunda (71.690) y La Nación (26.973) (ANP 2008). De estos cinco diarios, El Mercurio y La Tercera cubren temas más políticos y de interés nacional, a diferencia de La Cuarta y Las Últimas Noticias que cubren temas como farándula, entretención y hechos delictuales.

Tabla 1: Medios de comunicación que utilizan chilenos para informarse (1996-2008) (Porcentaje que consume "todos los días")

\begin{tabular}{lrrrrr}
\hline & 1996 & 1999 & 2002 & 2005 & 2008 \\
\hline TV Abierta & 83,5 & 84,1 & 79,4 & 79,1 & 76,0 \\
Radio & 73,6 & 71,1 & 68,3 & 60,1 & 55,0 \\
Diarios & 19,6 & 25,1 & 22,4 & 22,6 & 22,0 \\
TV Cable & - & 23,0 & 25,2 & 24,7 & - \\
Internet & - & - & 11,6 & 15,3 & 26,0 \\
\hline
\end{tabular}

Fuente: Marín, C.; Cordero, R. "Medios masivos, opinión pública y transformaciones en la democracia", 2009 y CNTV, Encuesta Nacional de Televisión.

Aunque los niveles de penetración de Internet alcanzaban casi al 40\% de la población en 2006 (WIP-Chile 2006), eran pocas las personas que utilizaban Internet diariamente para informarse, $1,6 \%$ en 2005 . Internet y la televisión por cable son los medios que menos se utilizan para obtener información. La radio y los diarios presentan niveles constantes de consumo. Entre 1996 y 2005 la televisión es el medio de comunicación que más usaban los chilenos para informarse. 


\section{EVIDENCIA EMPÍRICA}

En esta investigación utilizamos los datos de dos encuestas, la $3^{\mathrm{a}}$ y $4^{\mathrm{a}}$ Encuesta Nacional UDP, realizadas en 2007 y 2008, para analizar la aprobación presidencial. Realizamos cruces de variables socioeconómicas, políticas y de largo plazo con la aprobación presidencial. Además, vemos cómo el consumo de medios, separado por tipo de medio, afecta la aprobación presidencial. Las dos Encuesta Nacional UDP, de 2007 y 2008, nos permiten acceder a este tipo de información, pues otras encuestas no incluyen preguntas sobre consumo de medios. Finalmente, proponemos un modelo estadístico de regresión logit que nos permite derivar rigurosas conclusiones sobre las relaciones de causalidad en nuestra investigación.

Nuestra primera hipótesis postula que, controlando por otras variables, la aprobación presidencial entre los que se informan por televisión es distinta que entre los que no lo hacen. Pero la Tabla 2 muestra que el $75 \%$ de los chilenos ve televisión todos los días, por lo que resulta difícil comparar con aquellos que no ven televisión. De hecho, aquellos que nunca ven televisión o lo hacen sólo una o dos veces a la semana constituían en torno al $10 \%$ del total en 2007 y 2008.

Adicionalmente, la Tabla 2 muestra que no hay una relación evidente entre aprobación presidencial y el consumo de televisión, ni en 2007 ni en 2008. La aprobación de la Presidenta Bachelet mejoró de 41,3 a 52,8 entre 2007 y 2008. Esa mejora se dio en todos los grupos de consumo televisivo. No hay evidencia que el mayor consumo de televisión esté relacionado con niveles de aprobación distintos. Es más, queda claro que los niveles de aprobación de Bachelet aumentaron en la misma dirección y con similar intensidad entre todos los grupos de consumo televisivo entre 2007 y 2008.

Tabla 2: Aprobación presidencial y consumo de televisión, 2007-2008

\begin{tabular}{lcccccccr}
\hline \multirow{2}{*}{$\begin{array}{l}\text { Aprobación } \\
\text { presidencial }\end{array}$} & $\begin{array}{c}2 \text { o menos } \\
\text { días } \\
\text { (incluido } \\
\text { nunca) }\end{array}$ & $\begin{array}{c}\text { 3-6 días } \\
\text { por } \\
\text { semana }\end{array}$ & $\begin{array}{c}\text { Todos los } \\
\text { días }\end{array}$ & Total & $\begin{array}{c}2 \text { o menos } \\
\text { días } \\
\text { (incluido } \\
\text { nunca) }\end{array}$ & $\begin{array}{c}\text { 3-6 días } \\
\text { por } \\
\text { semana }\end{array}$ & $\begin{array}{c}\text { Todos los } \\
\text { días }\end{array}$ & Total \\
\hline Aprueba & \multicolumn{2}{c}{2007} & & & \multicolumn{2}{c}{2008} & \\
Desaprueba & 35,7 & 39,7 & 42,4 & 41,3 & 50 & 48,4 & 54,4 & 52,8 \\
No sabe & 47,8 & 49,7 & 49,9 & 49,7 & 38,7 & 40,4 & 36,7 & 37,6 \\
No contesta & 8,8 & 2,8 & 4,5 & 4,7 & 4,8 & 8,9 & 4,6 & 5,4 \\
Total (N) & 8,1 & 7,8 & 3,3 & 4,4 & 6,5 & 2,2 & 4,3 & 4,2 \\
& $100 \%$ & $100 \%$ & $100 \%$ & $100 \%$ & $100 \%$ & $100 \%$ & $100 \%$ & $100 \%$ \\
& $(10 \%)$ & $(14 \%)$ & $(76 \%)$ & $(1.302)$ & $(14 \%)$ & $(17 \%)$ & $68 \%)$ & $(1.300)$ \\
\hline
\end{tabular}

Fuente: Cálculos de los autores a partir de la Tercera y Cuarta Encuesta Nacional UDP, 20072008. 
Por tanto, no hay evidencia para sostener nuestra primera hipótesis. El consumo de televisión no parece estar asociado a diferencias en aprobación presidencial. Esto pudiera deberse a que la gran mayoría consume cotidianamente televisión, por lo que grupo que no consume es demasiado pequeño para constituir un grupo comparable. Por eso, pasamos a nuestra segunda hipótesis, que evalúa la aprobación presidencial y su relación con el consumo de diarios.

Nuestra segunda hipótesis señala que, controlando por otras variables, la aprobación presidencial entre aquellos que se informan por diarios es distinta que entre los que no lo hacen. La Tabla 3 muestra los niveles de aprobación presidencial y el consumo de diarios en 2007 y 2008. Sólo el 21,9\% en 2007 y 17\% en 2008 de los entrevistados indica informarse así todos los días. Es decir, el consumo de medios escritos es mucho menor que el consumo de televisión. Los que leen todos los días desaprueban más la gestión presidencial que aquellos que leen menos diarios. En 2007, por ejemplo, entre los que se informaban todos los días por el periódico, un 53,2\% desaprobaba a Bachelet y un 38,7\% la aprobaba. En 2008, la lectura de diarios y la aprobación presidencial también estaban negativamente correlacionadas. A mayor lectura de diarios, menor aprobación presidencial.

La relación entre desaprobación y lectura de diarios es lineal en la dirección esperada. Mientras más leen las personas, mayor es la desaprobación. Mientras menos leen, mayor es la aprobación. De hecho, su nivel de desaprobación mayor se observa entre aquellos que leen diarios todos los días (53,2 y 45,5 en 2007 y 2008 respectivamente). La tendencia muestra una pendiente en alza entre la intensidad del consumo de diarios y la desaprobación presidencial. Si bien la encuesta reflejó que la aprobación nacional de Bachelet subió en 2008 respecto a 2007, aquellos que leen diarios con más regularidad son más negativos respecto al desempeño presidencial en ambos años. La evidencia por tanto sí sustenta nuestra segunda hipótesis. Hay diferencias observables entre la minoría que se informa a través de los diarios regularmente y la mayoría que no lo hace.

Tabla 3: Aprobación presidencial y consumo de diarios, 2007-2008

\begin{tabular}{lrrrrrrrrrr}
\hline & $\begin{array}{c}2 \text { o } \\
\text { menos } \\
\text { días \% }\end{array}$ & $\begin{array}{c}\text { 3-6 días } \\
\text { por } \\
\text { semana }\end{array}$ & $\begin{array}{c}\text { Todos } \\
\text { los días }\end{array}$ & Total & $\mathrm{N}$ & $\begin{array}{c}2 \text { o } \\
\text { menos } \\
\text { días }\end{array}$ & $\begin{array}{c}3-6 \text { días } \\
\text { por } \\
\text { semana }\end{array}$ & $\begin{array}{c}\text { Todos } \\
\text { los días }\end{array}$ & Total & N \\
\hline Aprueba & 41,8 & 42,3 & 38,7 & 41,2 & 537 & 56,2 & 46,6 & 45,5 & 52,7 & 682 \\
Desaprueba & 48,8 & 48,7 & 53,2 & 49,5 & 645 & 34,4 & 42,4 & 45,5 & 37,6 & 489 \\
No sabe & 3,9 & 4,3 & 3,9 & 4,7 & 61 & 4,9 & 8,1 & 4,5 & 5,4 & 70 \\
No contesta & 4,2 & 4,7 & 4,2 & 4,5 & 59 & 4,5 & 3,0 & 4,5 & 4,3 & 55 \\
Total & $100 \%$ & $100 \%$ & $100 \%$ & $100 \%$ & 1.302 & $100 \%$ & $100 \%$ & $100 \%$ & $100 \%$ & 1.296 \\
(N) & $(59 \%)$ & $(18 \%)$ & $(22 \%)$ & $(100 \%)$ & & $(65 \%)$ & $(18 \%)$ & $(17 \%)$ & $(100 \%)$ & \\
\hline
\end{tabular}

Fuente: Cálculos de los autores a partir de la Tercera y Cuarta Encuesta Nacional UDP, 20072008. 
La tercera hipótesis sugiere que, controlando por otras variables, la aprobación presidencial entre aquellos que se informan por radio es distinta que entre los que no lo hacen. La Tabla 4 nuevamente muestra diferencias. El consumo diario de radios (55\% en 2007 y $47 \%$ en 2008) inferior al de televisión y superior al de diarios. Pero no hay una relación entre desaprobación y consumo de radios. Por lo tanto, no encontramos evidencia para nuestra tercera hipótesis. El consumo de radio parece no tener un efecto sobre la aprobación presidencial.

Tabla 4: Aprobación presidencial y consumo de radios

\begin{tabular}{lrrrrrrrrrr}
\hline $\begin{array}{c}2 \text { o } \\
\text { menos } \\
\text { días }\end{array}$ & $\begin{array}{c}\text { 3-6 días } \\
\text { por } \\
\text { semana }\end{array}$ & $\begin{array}{c}\text { Todos } \\
\text { los } \\
\text { días }\end{array}$ & Total & N & $\begin{array}{c}\text { 2o } \\
\text { menos } \\
\text { días }\end{array}$ & $\begin{array}{c}3-6 \text { días } \\
\text { por } \\
\text { semana }\end{array}$ & $\begin{array}{c}\text { Todos } \\
\text { los } \\
\text { días }\end{array}$ & Total & N \\
\hline & & & 2007 & & & & & 2008 & & \\
\hline Aprueba & 41,5 & 41,9 & 41,1 & 41,4 & 535 & 56,7 & 51,1 & 50,6 & 52,8 & 683 \\
Desaprueba & 46,9 & 51,1 & 50,2 & 49,6 & 641 & 36 & 36,9 & 39,1 & 37,7 & 488 \\
No sabe & 6,3 & 3,3 & 4,5 & 4,7 & 61 & 4,7 & 7,8 & 4,8 & 5,3 & 70 \\
No contesta & 5,3 & 3,7 & 4,1 & 4,3 & 56 & 2,6 & 4,1 & 5,5 & 4,2 & 55 \\
Total & $100 \%$ & $100 \%$ & $100 \%$ & $100 \%$ & 1.293 & $100 \%$ & $100 \%$ & $100 \%$ & $100 \%$ & 1.296 \\
& $(25 \%)$ & $(21 \%)$ & $(55 \%)$ & $(100 \%)$ & & $(33 \%)$ & $(21 \%)$ & $(47 \%)$ & & \\
\hline
\end{tabular}

Fuente: Cálculos de los autores a partir de la Tercera y Cuarta Encuesta Nacional UDP, 2007-2008.

El consumo de información a través de Internet todavía es un fenómeno poco extendido. De hecho, más de la mitad de la muestra dijo no usar Internet nunca o casi nunca como medio de información. Pero entre esa minoría que sí se informa por Internet, observamos una mayor desaprobación que en el resto de la población. Por lo tanto, también podemos identificar una relación entre "más consumo de medios, más desaprobación" en el caso de Internet.

Tabla 5: Aprobación presidencial y navegación por Internet

\begin{tabular}{|c|c|c|c|c|c|c|c|c|c|c|}
\hline & $\begin{array}{c}20 \\
\text { menos } \\
\text { días }\end{array}$ & $\begin{array}{c}\text { 3-6 días } \\
\text { por } \\
\text { semana }\end{array}$ & $\begin{array}{l}\text { Todos } \\
\text { los } \\
\text { días }\end{array}$ & Total & $\mathrm{N}$ & $\begin{array}{l}20 \\
\text { menos } \\
\text { días }\end{array}$ & $\begin{array}{l}\text { 3-6 días } \\
\text { por } \\
\text { semana }\end{array}$ & $\begin{array}{c}\text { Todos } \\
\text { los } \\
\text { días }\end{array}$ & Total & $\mathrm{N}$ \\
\hline & & & 2007 & & & & & 2008 & & \\
\hline Aprueba & 42,3 & 38,2 & 37,3 & 41,3 & 514 & 55,4 & 44,4 & 47,7 & 52,9 & 667 \\
\hline Desaprueba & 47,6 & 55,7 & 55 & 49,5 & 624 & 35,2 & 43,8 & 43,1 & 37,5 & 477 \\
\hline No sabe & 5,3 & 1,5 & 5 & 4,8 & 61 & 5,3 & 6,2 & 4,6 & 5,3 & 67 \\
\hline No contesta & 4,9 & 4,6 & 2,7 & 4,5 & 56 & 4,1 & 5,6 & 4,6 & 4,2 & 55 \\
\hline Total & $\begin{array}{l}100 \% \\
(72 \%)\end{array}$ & $\begin{array}{l}100 \% \\
(10 \%)\end{array}$ & $\begin{array}{l}100 \% \\
(17,5)\end{array}$ & $100 \%$ & 1.255 & $\begin{array}{l}100 \% \\
(70 \%)\end{array}$ & $\begin{array}{l}100 \% \\
(11 \%)\end{array}$ & $\begin{array}{c}100 \% \\
(19 \%)\end{array}$ & $100 \%$ & 1.266 \\
\hline
\end{tabular}

Fuente: Cálculos de los autores a partir de la Tercera y Cuarta Encuesta Nacional UDP, 2007-2008. 
En general, los datos muestran que un alto consumo de medios de comunicación no está asociado con la desaprobación en el caso de la televisión, radio e Internet, pero sí en el caso de los diarios, donde el consumo cotidiano está asociado con una mayor desaprobación. Pero como el porcentaje de personas que consume diarios con regularidad es sustancialmente inferior al de aquellos que consume información por radios o televisión, el efecto de polarización de los diarios es mucho menos extendido en la población. Más aún, como veremos más abajo, el mayor consumo de diarios está también relacionado con niveles de ingreso más elevado, donde la aprobación a Bachelet también era menor que en el resto de la población.

\section{SÚPER-INFORMADOS}

Ahora bien, las personas pueden consumir información a través de algunos o varios de los medios discutidos anteriormente. Ya que el consumo de televisión está ampliamente extendido pero el consumo de diarios es más restringido, agrupamos a aquellos que consumen información diariamente tanto a través de diarios como de televisión. La Tabla 6 muestra un cruce entre aquellos que consumen televisión y los que consumen diarios. Aquellos que consumen televisión todos los días (75,7\% y 68,4 en 2007 y 2008 respectivamente) son muchos más que los que leen diarios todos los días (22 y 17\% respectivamente). El grupo que consume televisión y también lee diarios todos los días constituye un $19 \%$ en 2007 y un $14 \%$ en 2008 del total de la muestra. De acuerdo a lo que suponemos a partir de la discusión teórica, ese grupo, al que denominamos súperinformados, debiese demostrar un comportamiento político distinto al resto de la población. Si efectivamente los medios de comunicación tienen un efecto sobre las personas, el grupo de aquellos que más medios de comunicación consume debiese tener posiciones que son sistemáticamente diferentes que aquellos que consumen menos medios.

Tabla 6: Los chilenos y su consumo de medios para informarse

\begin{tabular}{|c|c|c|c|c|c|c|}
\hline Consumo de medios & $\begin{array}{l}\text { Ve TV } \\
\text { todos los } \\
\text { días } \\
\% \\
\text { (n) }\end{array}$ & $\begin{array}{l}\text { Ve TV } \\
\text { menos que } \\
\text { todos los } \\
\text { días } \\
\% \\
\text { (n) }\end{array}$ & $\begin{array}{c}\text { Total } \\
\% \\
\text { (n) }\end{array}$ & $\begin{array}{c}\text { Ve TV todos } \\
\text { los días } \\
\% \\
\text { (n) }\end{array}$ & $\begin{array}{l}\text { Ve TV } \\
\text { menos que } \\
\text { todos los } \\
\text { días } \\
\% \\
\text { (n) }\end{array}$ & $\begin{array}{c}\text { Total } \\
\% \\
\text { (n) }\end{array}$ \\
\hline & \multicolumn{3}{|c|}{2007} & \multicolumn{3}{|c|}{2008} \\
\hline Lee diarios todos los días & $\begin{array}{c}19,0 \% * \\
(247)\end{array}$ & $\begin{array}{c}2,9 \% \\
(38)\end{array}$ & $\begin{array}{c}21,9 \% \\
(285)\end{array}$ & $\begin{array}{c}14,3 \% * \\
(185)\end{array}$ & $\begin{array}{c}2,9 \% \\
(37)\end{array}$ & $\begin{array}{c}17,2 \% \\
(222)\end{array}$ \\
\hline Lee diarios ocasionalmente & $\begin{array}{c}36,3 \% \\
(472)\end{array}$ & $\begin{array}{c}10,7 \% \\
(139)\end{array}$ & $\begin{array}{c}46,9 \% \\
(611)\end{array}$ & $\begin{array}{c}34,6 \% \\
(448)\end{array}$ & $\begin{array}{c}18,2 \% \\
(235)\end{array}$ & $\begin{array}{c}52,8 \% \\
(683)\end{array}$ \\
\hline Lee diarios casi nunca & $\begin{array}{c}20,4 \% \\
(266)\end{array}$ & $\begin{array}{l}8,1 \% \\
(105)\end{array}$ & $\begin{array}{c}28,5 \% \\
(371)\end{array}$ & $\begin{array}{c}19,5 \% \\
(252)\end{array}$ & $\begin{array}{c}10,6 \% \\
(135)\end{array}$ & $\begin{array}{c}30,1 \% \\
(389)\end{array}$ \\
\hline Total & $\begin{array}{c}75,7 \% \\
(985)\end{array}$ & $\begin{array}{c}24,3 \% \\
(316)\end{array}$ & $\begin{array}{c}100 \% \\
(1.301)\end{array}$ & $\begin{array}{c}68,4 \% \\
(885)\end{array}$ & $\begin{array}{c}31,6 \% \\
(409)\end{array}$ & $\begin{array}{c}100 \% \\
(1.294)\end{array}$ \\
\hline
\end{tabular}

Fuente: Cálculos de los autores a partir de la Tercera y Cuarta Encuesta Nacional UDP, 2007-2008.

* Súper-informados. 
Como muestra la Tabla 7, la aprobación presidencial en el grupo de "súper informados" ( $\mathrm{N}=247$ ) fue de $38,5 \%$ en 2007, un valor menor al de la media nacional (41.3\%). A su vez, la desaprobación entre el grupo de "súper informados" es de 53,8\%, sustancialmente mayor a la media del país (49,5\%). En 2008, la aprobación de Bachelet subió en todos los grupos, pero siguió siendo inferior entre los súper-informados $(44,3 \%)$ que en la población en general (52,7\%). Esto es consistente con las tres hipótesis planteadas anteriormente, mientras más se informan las personas, más intensas son sus posturas respecto al desempeño presidencial.

Tabla 7: Súper informados y aprobación presidencial

\begin{tabular}{lrrrrrr}
\hline & $\begin{array}{c}\text { Súper } \\
\text { informados }\end{array}$ & $\begin{array}{c}\text { Resto de la } \\
\text { población }\end{array}$ & Total & $\begin{array}{c}\text { Súper } \\
\text { informados }\end{array}$ & $\begin{array}{c}\text { Resto de la } \\
\text { población }\end{array}$ & Total \\
\hline Aprueba & \multicolumn{7}{c}{2007} & & & 2008 & \\
Desaprueba & 38,5 & 42,0 & 41,3 & 44,3 & 54,1 & 52,7 \\
No sabe & 53,8 & 48,5 & 49,5 & 45,4 & 36,3 & 37,6 \\
No contesta & 4,5 & 4,7 & 4,7 & 5,4 & 5,4 & 5,4 \\
Total & 3,2 & 4,7 & 4,5 & 4,9 & 4,2 & 4,3 \\
& $100 \%$ & $100 \%$ & 1.301 & $100 \%$ & $100 \%$ & $100 \%$ \\
& $(247)$ & $(1.054)$ & $(100 \%)$ & $(185)$ & $(1.109)$ & 1.294 \\
\hline
\end{tabular}

Fuente: Cálculos de los autores a partir de la Tercera y Cuarta Encuesta Nacional UDP, 2007-2008.

\section{ACCESO A LA INFORMACIÓN COMO VARIABLE DEPENDIENTE}

Como resulta lógico suponer, aquellas personas mejor informadas (súper informados) tienen mayor presencia entre los sectores de más ingresos. Los niveles de educación y el ingreso monetario influyen en su consumo de medios. Hay más personas en los segmentos de ingresos medio-bajos y bajos (C3, D y E) que en segmentos medios (C2) y alto $(\mathrm{ABC} 1)$. Mientras más alto el segmento socioeconómico, más alto el porcentaje de 'súper-informados'.

Las explicaciones del comportamiento electoral que se desarrollan a partir de los modelos Columbia y Michigan suponen que la condición socioeconómica o de clase, o la socialización, determinan sus posturas políticas. Los datos que aquí analizamos son consistentes con esa premisa. Como muestra la Figura 2, la aprobación a Bachelet era superior entre los grupos de menos ingresos. Pero dentro de cada grupo socioeconómico, la aprobación presidencial tendía a ser levemente inferior entre los super-informados que en el resto. Salvo en el grupo de clase media-baja (C3), donde los súper informados exhiben una aprobación marginalmente superior al resto, las personas que se informan cotidianamente por la televisión y por los diarios exhiben niveles de aprobación inferior. Por cierto, aunque visualmente no se pueden observar en la Figura 2, los grupos C3 y D son los más numerosos en la población (37,3\% y 44,3\%, respectivamente). 
Figura 2: Aprobación presidencial por GSE y por nivel de información de las personas

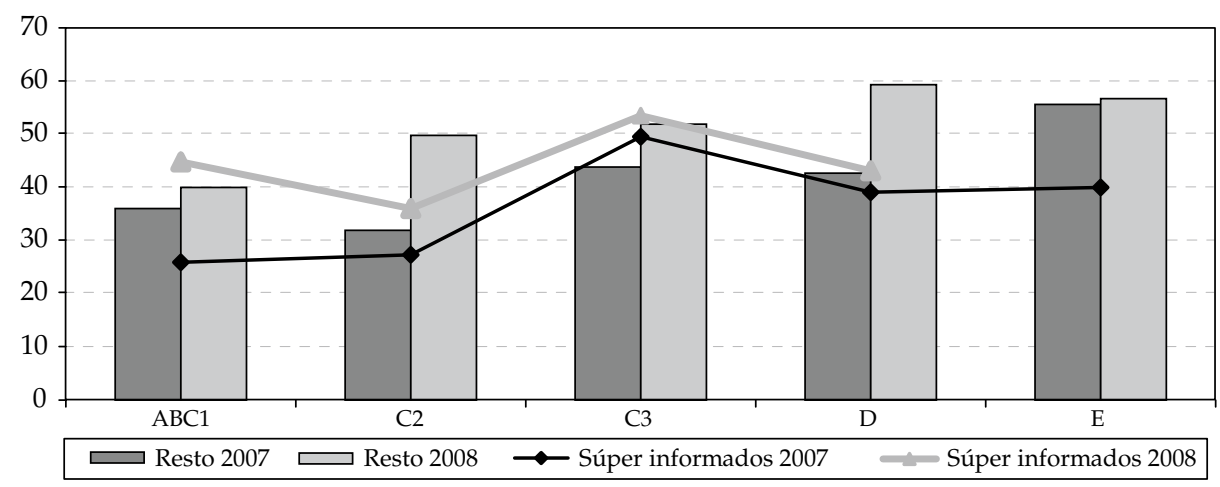

Fuente: Cálculos de los autores a partir de la Tercera y Cuarta Encuesta Nacional UDP, 2007-2008.

El Modelo Columbia sugiere que las personas heredan sus predisposiciones políticas. Su percepción sobre la realidad está influida por dicha inclinación inicial. Así, independientemente de la situación económica, las personas con inclinación política de izquierda debieran estar más predispuestas a aprobar el desempeño de Bachelet que aquellas con predisposición de derecha. Ahora bien, el porcentaje de personas que no se identifica con ningún sector $(43,9 \%)$ es más alto que el que se identifica con uno de los sectores tradicionalmente asociados con la política chilena -derecha de 13,7\%, centro de 15,3\% e izquierda 16,0 en 2007. Como muestra la Figura 3, entre aquellos que se identifican con la izquierda o centro, la aprobación a Bachelet es superior que en el resto de la población. No obstante, aquellos más informados muestran un nivel de aprobación inferior a los que están menos informados en cada uno de los grupos ideológicamente alineados. Incluso la aprobación presidencial es menor en el grupo de los 'súper informados' de izquierda que en el grupo de los menos informados de ese sector.

Figura 3: Aprobación presidencial por identificación política

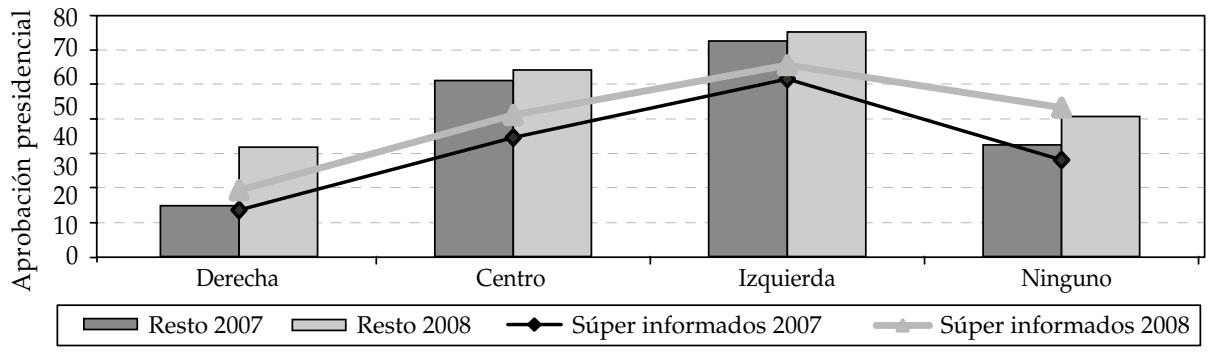

Fuente: Cálculos de los autores a partir de la Tercera y Cuarta Encuesta Nacional UDP, 2007-2008. 
Ahora bien, las explicaciones sobre el comportamiento electoral que se construyen a partir del Modelo Rochester -esto es, que las personas reaccionan a variables de corto plazo, como el desempeño económico, la inflación o el desempleo- suponen que la aprobación presidencial debiera estar determinada por las percepciones sobre el desempeño económico. Si esas percepciones individuales son negativas, su aprobación del desempeño presidencial también debiese ser menor. La Figura 4 muestra que la evidencia también es consistente con el Modelo Rochester. Los niveles de aprobación presidencial disminuyen a medida que empeora la percepción de las personas sobre la economía.

Pero la relación entre percepción económica y aprobación presidencial parece ser afectada también por el acceso a la información. En el grupo que considera la situación económica como buena o muy buena, los niveles de aprobación son similares entre aquellos que están más informados y el resto. Pero en los grupos que consideran que la situación económica es regular o mala, los más informados muestran una aprobación inferior al resto. Esto es consistente con el Modelo Rochester, que supone el comportamiento racional de votantes cuya percepción política está inducida por el desempeño económico. Pero también hay evidencia de que el consumo de medios afecta negativamente la aprobación presidencial al interior de cada grupo. En el grupo que más medios consume, más baja es la aprobación, tanto entre los que creen que la economía anda bien como en aquellos que la perciben como regular o de mal desempeño.

Figura 4: Aprobación presidencial por percepción económica

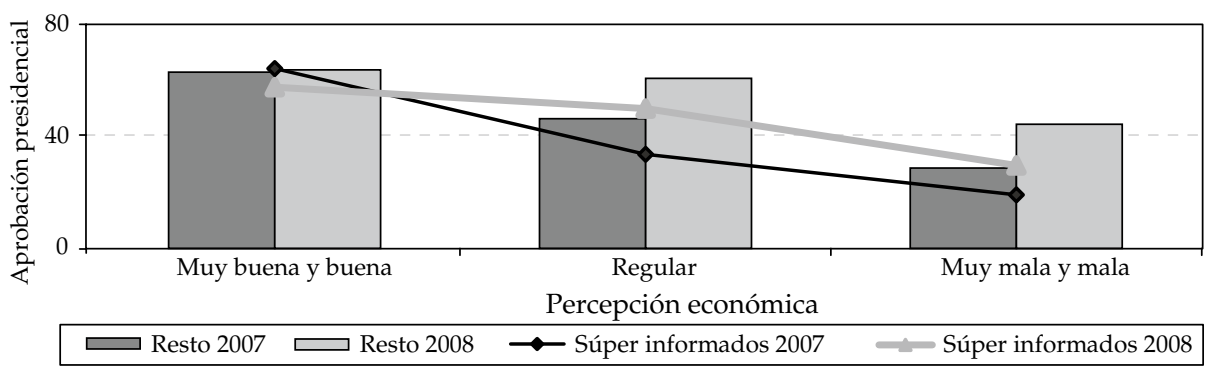

Fuente: Cálculos de los autores a partir de la Tercera Encuesta Nacional UDP, 2007.

A partir de las Figuras 2-4, podemos concluir que si bien hay evidencia de que la opinión pública se comporta de forma consistente con las explicaciones de largo y mediano plazo de los modelos Columbia y Michigan, pero también con las explicaciones de voto económico del Modelo Rochester. Pero también hay evidencia de que el consumo de medios está correlacionado con un efecto diferenciado sobre la aprobación presidencial, controlando por otras variables. Si bien las personas que heredan atributos de izquierda muestran una aprobación presidencial superior al resto, los izquierdistas 'súper informados' presentan niveles de aprobación inferiores al resto de izquierdistas. Lo mismo ocurre con aquellos que, siendo menos proclives a aprobar el desempeño presidencial porque consideran que la situación económica es regular o mala, están más informados que sus pares. A mayor información, menores son los niveles de aprobación en todas las categorías. 


\section{MODELO ESTADÍSTICO}

A continuación presentamos un modelo estadístico de regresión logit que muestra resultados consistentes con lo anteriormente descrito. La Tabla 8 muestra, con una metodología estadísticamente más rigurosa (aunque también menos intuitiva y visualmente menos gráfica), y controlando por el efecto de todas las variables en forma simultánea, algo similar a lo que argumentamos a partir de las figuras y tablas de la sección anterior. Pero ya que incorporamos una regresión logística que evalúa el efecto de las variables independientes controlando por otras variables independientes, llegamos a conclusiones más robustas sobre el efecto que el consumo de medios está teniendo sobre la aprobación presidencial en los chilenos.

La Tabla 8 incorpora variables de corto y largo plazo, indicadores sociodemográficos y consumo de medios escritos y televisivos en un modelo explicativo de la aprobación al desempeño de la Presidenta Bachelet. El Modelo 1 explica la aprobación presidencial a partir de variables sociodemográficas. Los hombres son menos proclives a aprobar a Bachelet que las mujeres (nuestro grupo de referencia en este modelo). A su vez, entre los más jóvenes y los adultos entre 30-45 años hay un menor nivel de aprobación que entre las personas de más edad. Esta evidencia es consistente con el Modelo Columbia, que sugiere que las percepciones políticas están influidas por atributos heredados. Las personas de más altos ingresos son menos proclives a apoyar a una Presidenta de izquierda asociada con la defensa de los intereses de sectores de menos ingresos.

Asimismo en los estratos de más altos ingresos ( $\mathrm{ABC} 1$ y $\mathrm{C} 2$ ) hay una marcada baja presencia de bacheletistas en comparación a los estratos más bajos. Como era de esperar, las personas que consideran que la situación económica es muy buena y buena son mucho más bacheletistas que aquellos que tienen una evaluación negativa sobre la economía. Esta evidencia es a su vez consistente con el Modelo Rochester, que sugiere que variables de corto plazo (como la percepción de las personas sobre la economía) determina su evaluación sobre el desempeño presidencial.

El Modelo 2 explica la aprobación presidencial a partir de variables sociodemográficas y políticas, pero no incluye la percepción individual sobre situación económica del país. Los hombres siguen siendo menos proclives a aprobar el desempeño de la Presidenta que las mujeres. Los jóvenes y los adultos entre 30-45 años también son menos bacheletistas que los de tercera edad. Al agregar variables políticas y excluir variables sobre situación económica, los coeficientes del nivel socioeconómico se mueven en su significancia y en el beta. Los entrevistados que pertenecen al grupo $\mathrm{ABC} 1, \mathrm{C} 2$ y D (éste último con un nivel de significancia menor) presentan niveles fuertemente inferiores de aprobación en comparación al grupo de referencia "E". Por otro lado, las personas que se identifican con la Concertación aprueban mucho más a Bachelet en comparación a las personas que se identifican con "ninguna" coalición. En cambio, los aliancistas y las personas que se identifican con el izquierdista pacto Juntos Podemos, aprueban mucho menos a Bachelet que los que no se identifican con ningún pacto político. El Modelo 2 parece sustentar las explicaciones consistentes con la Escuela Columbia, la probabilidad de aprobar el 
desempeño presidencial está fuertemente ligada a la identificación política inicial de las personas. El hecho de que las personas de más ingresos estén menos inclinadas a aprobar el desempeño presidencial también parece sustentar las explicaciones que dan cuenta del comportamiento político de las personas a partir de su condición de clase.

El Modelo 3 explica la aprobación presidencial a partir de variables sociodemográficas y políticas. Además, incluimos la percepción sobre la situación económica. Los hombres siguen aprobando menos a Bachelet que las mujeres. Así también los jóvenes y las personas entre 30 y 45 años son menos bacheletistas que los más adultos. Los coeficientes para el caso del nivel socioeconómico son similares al Modelo 2 aunque más pronunciados. Todos los grupos desaprueban más que el grupo de referencia "E", siendo los más acomodados quienes desaprueban aún más fuertemente. Así también, las personas que consideran que la situación económica es buena y regular aprueban más en comparación a los que consideran que la situación económica es negativa. En la identificación con las coaliciones, tanto los concertacionistas como los adherentes al pacto Juntos Podemos, aprueban más a Bachelet que las personas que no adhieren a algún pacto. La postura de los que se identifican con la Alianza respecto a la aprobación presidencial sigue siendo fuertemente negativa en comparación a quienes no se identifican con ninguna coalición.

Los Modelos 1-3 tienen una buena capacidad predictiva (entre el 64,8 y el 71\% de las observaciones son predichas correctamente), y las diferencias entre los distintos modelos no son de una magnitud alta. Esto es, el comportamiento político de los chilenos puede ser explicado tanto por teorías consistentes con el Modelo Rochester como por aquellas que se basan en los modelos de Columbia y Michigan. El Modelo 4 incorpora, además de las variables sociodemográficas, políticas y de percepción económica, el consumo de los distintos diarios. Para este caso, las variables sociodemográficas mantienen el mismo efecto sobre la aprobación presidencial. Solo disminuyen los coeficientes en el nivel socioeconómico, aunque los niveles de significancia son bajos. Así también la situación económica y la identificación con coaliciones se mantiene igual. En el consumo de diarios, la gente que lee La Tercera y El Mercurio presenta niveles de aprobación menores que las personas que no consumen ningún medio (nuestro grupo de referencia). El resto de los diarios no presenta niveles de significancia suficientes que nos permita identificar diferencias.

El Modelo 5 contiene el consumo de medios televisivos, además de variables sociodemográficas, políticas, situación económica y consumo de medios escritos. Las variables sociodemográficas siguen manteniendo signos similares a los modelos anteriores. Así también, el nivel socioeconómico, la identificación con coaliciones y situación económica se mantienen con coeficientes similares. En el análisis de los medios, las personas que consumen La Tercera y El Mercurio mantienen niveles de aprobación negativos respecto a los que no consume ningún medio. Finalmente en el consumo de televisión, los canales TVN y CHV (aunque este último con un nivel de significancia menor) tienen un nivel de aprobación superior al de los entrevistados que consumen Megavisión (nuestro grupo de referencia). 
Tabla 8: Modelos de regresión logística con consumo de medios y variables de corto y largo plazo sobre la aprobación presidencial de Bachelet, 2007

\begin{tabular}{|c|c|c|c|c|c|}
\hline & $\begin{array}{l}\text { Modelo } 1 \\
\text { (Michigan) }\end{array}$ & $\begin{array}{l}\text { Modelo } 2 \\
\text { (coaliciones) }\end{array}$ & $\begin{array}{l}\text { Modelo } 3 \\
\text { (coalición + } \\
\text { situación } \\
\text { económica) }\end{array}$ & $\begin{array}{c}\text { Modelo 4 } \\
\text { (Modelo 3+ } \\
\text { consumo de } \\
\text { diarios) }\end{array}$ & $\begin{array}{l}\text { Modelo } 5 \\
\text { (Modelo 4 + } \\
\text { más TV) }\end{array}$ \\
\hline Sexo, hombres (a) & $-0,369^{* * *}$ & $-0,295^{* * *}$ & $-0,451^{* * *}$ & $-0,471^{* * *}$ & $-0,413^{* * *}$ \\
\hline \multicolumn{6}{|l|}{ Edad (b) } \\
\hline $18-29$ & $-0,534^{* * *}$ & $-0,266^{* *}$ & $-0,463^{* *}$ & $-0,441^{* *}$ & $-0,432+$ \\
\hline $30-45$ & $-0,492^{* * *}$ & $-0,302^{* * *}$ & $-0,513^{* * *}$ & $-0,458^{* *}$ & $-0,448^{* *}$ \\
\hline $46-60$ & $-0,135$ & $-0,082$ & $-0,123$ & $-0,097$ & $-0,012$ \\
\hline \multicolumn{6}{|l|}{ NSE (c) } \\
\hline $\mathrm{ABC1}$ & $-2,081^{* * *}$ & $-1,919^{* * *}$ & $-2,470^{* * *}$ & $-2,182^{* * *}$ & $-2,056^{* * *}$ \\
\hline C2 & $-1,708^{* * *}$ & $-1,538^{* * *}$ & $-1,869^{* * *}$ & $-1,654^{* *}$ & $-1,707^{* *}$ \\
\hline $\mathrm{C} 3$ & $-0,805$ &,- 944 & $-1,018$ & $-0,883$ & $-0,939$ \\
\hline $\mathrm{D}$ & $-0,754$ & $-1,124+$ & $-1,051+$ & $-0,963$ & $-0,972$ \\
\hline \multicolumn{6}{|c|}{ Situación económica del país (d) } \\
\hline Muy buena + Buena & $2,031^{* * *}$ & & $1,852^{* * *}$ & $1,920^{* * *}$ & $1,902^{* * *}$ \\
\hline Regular & 0,985 & & $0,839^{* * *}$ & $0,861^{* * *}$ & $0,917^{* * *}$ \\
\hline \multicolumn{6}{|c|}{ Identificación con partidos coaliciones políticas (e) } \\
\hline Alianza por Chile & & $-0,930^{* * *}$ & $-0,895^{* * *}$ & $-0,828^{* * *}$ & $-0,797^{* * *}$ \\
\hline Concertación & & $1,510^{* * *}$ & $1,351^{* * *}$ & $1,392^{* * *}$ & $1,369^{* * *}$ \\
\hline Juntos Podemos & & $0,615^{* *}$ & $0,617^{* *}$ & $0,642^{* *}$ & $0,803^{* *}$ \\
\hline \multicolumn{6}{|c|}{ Por cuáles diarios se informa (f) } \\
\hline La Nación & & & & 0,124 & $-0,587$ \\
\hline La Tercera & & & & $-0,489^{* *}$ & $-0,520^{* *}$ \\
\hline El Mercurio & & & & $-0,633^{* *}$ & $-0,604^{* *}$ \\
\hline LUN & & & & $-0,320$ & $-0,344$ \\
\hline Otros & & & & $-0,341$ & $-0,393$ \\
\hline La Cuarta & & & & $-0,263$ & $-0,182$ \\
\hline La Hora/Publimetro & & & & $-0,327$ & $-0,519$ \\
\hline \multicolumn{6}{|c|}{ Por cuáles canales de televisión se informa (g) } \\
\hline CHV & & & & & $0,469+$ \\
\hline La Red & & & & & 0,464 \\
\hline TVN & & & & & $0,747^{* * *}$ \\
\hline Canal 13 & & & & & 0,362 \\
\hline Constante & $0,182^{* * *}$ & $0,178^{* * *}$ & $0,178^{* * *}$ & $0,181^{* * *}$ & $0,167^{* * *}$ \\
\hline Chi cuadrado & $150,153^{* * *}$ & $255,388^{* * *}$ & $255,754^{* * *}$ & $262,096^{* * *}$ & $261,853^{* * *}$ \\
\hline $\begin{array}{l}-2 \log \text { de verosimilitud } \\
\text { final }\end{array}$ & $1.478,882$ & $1.255,547$ & $1.255,180$ & $1.234,430$ & $1.156,065$ \\
\hline $\begin{array}{l}\text { R cuadrado de Cox y } \\
\text { Snell }\end{array}$ & 0,159 & 0,208 & 0,208 & 0,214 & 0,225 \\
\hline $\begin{array}{l}\text { R cuadrado de } \\
\text { Nagelkerke }\end{array}$ & 0,119 & 0,278 & 0,278 & 0,287 & 0,301 \\
\hline $\begin{array}{l}\text { Porcentaje pronosticado } \\
\text { correcto }\end{array}$ & 64,8 & 71 & 70,9 & 71,3 & 72 \\
\hline
\end{tabular}

$\left.{ }^{* * *}\right)$ Significante al $\left.\mathrm{p} \leq 0,01 .{ }^{* *}\right)$ Significante al $\mathrm{p} \leq 0,05 ;(+)$ Significante al $\mathrm{p} \leq 0,1$.

Las categorías de referencia son (a) "mujer"; (b) "61 y más"; (c) "E"; (d) "Muy malo + Malo"; (e) "Ninguno"; (f) "Ninguno"; (g) "Megavisión".

Fuente: Cálculos de los autores a partir de la Tercera Encuesta Nacional UDP, 2007. 
Los Modelos 4 y 5 muestran el efecto que tiene el consumo de medios sobre la aprobación presidencial, controlando por variables sociodemográficas y políticas de corto y largo plazo. La evidencia parece indicar que el consumo de medios tiende a profundizar las predisposiciones políticas iniciales. Las personas que leen los dos principales diarios (El Mercurio y La Tercera) presentan menores niveles de aprobación presidencial que aquellos que no leen diarios. A su vez aquellos que consumen información a través de Televisión Nacional, y en menor grado de Chilevisión, presentan niveles de aprobación presidencial superiores que los que no ven televisión. Como ya mencionamos, el consumo de televisión está mucho más extendido que el de diarios, por lo que el efecto marginal del consumo de diarios parece más importante. Las personas que consumen información de diarios tienden a presentar niveles de aprobación presidencial inferiores a los que no consumen información a través de La Tercera o El Mercurio.

Realizamos el mismo ejercicio con los datos de la Cuarta Encuesta Nacional UDP, de 2008. La aprobación presidencial subió de 41,3\% en 2007 a 52,7\% en 2008. A su vez, la desaprobación nacional cayó de 49,5 a 37,6\% en el mismo período. Los resultados de la Tabla 9 muestran que los determinantes de aprobación presidencial se mantuvieron con los mismos signos en ambos años. Naturalmente, la magnitud del efecto de algunos de ellos cambió en la medida que la aprobación presidencial también cambió. Dado que en 2008 hubo una aprobación presidencial mayor, hay menos coeficientes significativos en 2008 que en 2008. Esto porque al existir mayor aprobación, las diferencias más notorias en rechazo a Bachelet entre los más jóvenes respecto a los adultos, por ejemplo, tendieron a diluirse. Si en 2007 las personas de más edad tendían a aprobar más que las de menos edad el desempeño presidencial que los más jóvenes, en 2008 la aprobación de Bachelet tendió a ser más pareja, y más alta, entre todos los grupos de edad.

Pero las diferencias entre los niveles de aprobación de las personas que más se informan por medios de comunicación se mantuvieron respecto a 2007. Aquellos que se informan diariamente por medios impresos mostraron consistentemente niveles más bajos de aprobación que el resto de la población. La lectura de diarios está negativamente correlacionada con la aprobación presidencial, controlando por otras variables. Pero estos datos son solo estadísticamente significativos para los medios La Tercera y El Mercurio, igual que en 2007.

Igual que en 2007, el consumo de televisión también afecta positivamente la aprobación presidencial. Pero a diferencia de 2007, en 2008 esa relación no es estadísticamente significativa. Por ello, si en 2007 pudimos ver que el consumo de TVN repercutía positivamente en los niveles de aprobación presidencial, en 2008 ese efecto positivo no es estadísticamente significativo.

De cualquier forma, tanto en 2007 como en 2008 el consumo de diarios produce un nivel menor de aprobación presidencial, controlando por otras variables asociadas con los modelos de Columbia, Michigan y Rochester. Esto quiere decir que si bien hay una serie de variables que inducen a las personas a aprobar o rechazar la gestión presidencial, el consumo de diarios induce a la gente a mostrar menor nivel de aprobación. Mientras más diarios consumen las personas, controlando por otras variables, menor es su aprobación presidencial. 
Tabla 9: Modelos de regresión logística con consumo de medios y variables de corto y largo plazo sobre la aprobación presidencial de Bachelet, 2008

\begin{tabular}{|c|c|c|c|c|c|}
\hline & $\begin{array}{l}\text { Modelo } 1 \\
\text { (Michigan) }\end{array}$ & $\begin{array}{l}\text { Modelo } 2 \\
\text { (coaliciones) }\end{array}$ & $\begin{array}{l}\text { Modelo } 3 \\
\text { (coalición + } \\
\text { situación } \\
\text { económica) }\end{array}$ & $\begin{array}{l}\text { Modelo 4 } \\
\text { (Modelo 3+ } \\
\text { consumo de } \\
\text { diarios) }\end{array}$ & $\begin{array}{l}\text { Modelo } 6 \\
\text { (Modelo 4 + } \\
\text { más TV) }\end{array}$ \\
\hline Sexo, hombres (a) & $-0,249^{* *}$ & $-0,153$ & $-0,297^{* *}$ & $-0,286^{* *}$ & $-0,265^{* *}$ \\
\hline \multicolumn{6}{|l|}{ Edad (b) } \\
\hline $18-29$ & 0,035 & 0,240 & 0,147 & 0,178 & 0,227 \\
\hline $30-45$ & $-0,079$ & 0,085 & 0,008 & 0,038 & 0,055 \\
\hline $46-60$ & 0,027 & 0,066 & 0,036 & 0,032 & 0,074 \\
\hline \multicolumn{6}{|l|}{ NSE (c) } \\
\hline $\mathrm{ABC1}$ & $-0,926^{* * *}$ &,- 533 & $-0,765^{* *}$ & $-0,731^{* *}$ & $-0,808^{* *}$ \\
\hline $\mathrm{C} 2$ & $-0,564^{* *}$ &,- 434 & $-0,569^{* *}$ & $-0,547^{* *}$ & $-0,562^{* *}$ \\
\hline $\mathrm{C} 3$ & $-0,289$ &,- 272 & $-0,316$ & $-0,319$ & $-0,321$ \\
\hline $\mathrm{D}$ & 0,021 &,- 041 & $-0,005$ & 0,032 & 0,006 \\
\hline \multicolumn{6}{|c|}{ Situación económica del país (d) } \\
\hline Muy buena + Buena & $1,105^{* * *}$ & & $0,911^{* * *}$ & $0,929^{* * *}$ & $1,902^{* * *}$ \\
\hline Regular & $0,815^{* * *}$ & & $0,765^{* * *}$ & $0,782^{* * *}$ & $0,917^{* * *}$ \\
\hline \multicolumn{6}{|c|}{ Identificación con partidos coaliciones políticas (e) } \\
\hline Alianza por Chile & & $-1.010^{* * *}$ & $-0,979 * * *$ & $-0,983^{* * *}$ & $-0,967^{* * *}$ \\
\hline Concertación & & $1.093^{* * *}$ & $0,985^{* * *}$ & $0,950^{* * *}$ & $0,935^{* * *}$ \\
\hline Juntos Podemos & & $0,606^{* *}$ & $0,529+$ & $0,508^{* *}$ & 0,453 \\
\hline \multicolumn{6}{|c|}{ Por cuales diarios se informa (f) } \\
\hline La Nación & & & & $-0,204$ & $-0,105$ \\
\hline La Tercera & & & & $-0,117$ & $-0,159^{* *}$ \\
\hline El Mercurio & & & & $-0,143$ & $-0,154^{* *}$ \\
\hline LUN & & & & $-0,134$ & $-0,115$ \\
\hline La Cuarta & & & & $-0,195$ & $-0,195$ \\
\hline Otros & & & & $-0,065$ & 0,20 \\
\hline \multicolumn{6}{|c|}{ Por cuales canales de televisión se informa (g) } \\
\hline $\mathrm{CHV}$ & & & & & 0,436 \\
\hline La Red & & & & & 0,172 \\
\hline TVN & & & & & $0,749+$ \\
\hline Canal 13 & & & & & 0,438 \\
\hline Megavisión & & & & & 0,228 \\
\hline Otros & & & & & 0,296 \\
\hline Constante & $0,105+$ & $0,146^{* *}$ & $0,141^{* * *}$ & $0,139^{* *}$ & $0,145^{* * *}$ \\
\hline Chi cuadrado & $68,612^{* * *}$ & $124,775^{* * *}$ & $161.809^{* * *}$ & $161,095^{* * *}$ & $171,009^{* * *}$ \\
\hline $\begin{array}{l}-2 \text { log de verosimilitud } \\
\text { final }\end{array}$ & $1.725,424$ & $1.534,576$ & $1.492,924$ & $1.475,735$ & $1.460,507$ \\
\hline $\begin{array}{l}\text { R cuadrado de Cox y } \\
\text { Snell }\end{array}$ & 0,052 & 0,099 & 0,126 & 0,127 & 0135 \\
\hline $\begin{array}{l}\text { R cuadrado de } \\
\text { Nagelkerke }\end{array}$ & 0,069 & 0,132 & 0,169 & 0,170 & 0,180 \\
\hline $\begin{array}{l}\text { Porcentaje pronosticado } \\
\text { correcto }\end{array}$ & 60,6 & 62,1 & 65,4 & 64,6 & 65,5 \\
\hline
\end{tabular}

${ }^{(* *)}$ Significante al $p \leq 0,01 .(* *)$ Significante al $p \leq 0,05 ;(+)$ Significante al $p \leq 0,1$.

Las categorías de referencia son (a) "mujer"; (b) "61 y más"; (c) "E"; (d) "Muy malo + Malo"; (e) "Ninguno"; (f) "Ninguno"; (g) "Ninguno".

Fuente: Cálculos de los autores a partir de la Cuarta Encuesta Nacional UDP, 2008. 
Ahora bien, como ya discutimos, pudiera ser que el consumo de diarios es a su vez producto de las predisposiciones políticas de las personas. Pero aún si fuera el caso, el hecho que el consumo de diarios esté relacionado con menor aprobación sugiere que la lectura de diarios al menos profundiza las predisposiciones ya existentes. Como también verificamos en modelos que no incluimos aquí, el mismo fenómeno ocurre cuando utilizamos la desaprobación presidencial como variable dependiente. A mayor consumo de diarios, mayor es la desaprobación.

\section{CONCLUSIÓN}

A partir de la evidencia presentada, parece ser o bien que el consumo de diarios induce a la gente a tener posiciones más extremas o bien que las personas utilizan la información de los medios de comunicación para reforzar sus posiciones políticas iniciales. Esta evidencia es consistente con los modelos Columbia y Michigan, que sugieren que los individuos heredan sus predisposiciones políticas o que las adquieren a través de socialización de mediano plazo. De cualquier forma, los chilenos bien pudieran estar seleccionando los medios y utilizando su información para reafirmar sus predisposiciones políticas. De acuerdo a lo que postulan los modelos Columbia y Michigan, las personas tendrían posiciones políticas definidas. Esas posiciones los inducen a consumir determinados medios, especialmente diarios. Luego de consumir esos medios, esas posiciones se refuerzan. Aquellas personas que consumen frecuentemente información de los medios ("súper informados") aprueban o rechazan el desempeño presidencial de manera más enfática que el resto. Por ejemplo, aquellas personas que son de derecha y que están en la condición de "súper informados" tienden a aprobar menos al gobierno que el resto de los derechistas.

Pero el Modelo Rochester, que sugiere que hay variables de corto plazo que influyen en la percepción política de las personas, también es consistente con la evidencia. Hay evidencia de que aquellas personas que están más informadas tienden a desaprobar el desempeño presidencial a partir de su apreciación negativa sobre la situación económica del país están también más informadas. Esto parece indicar que la información que presentan los medios de comunicación -especialmente los dos periódicos más leídos y tradicionalmente asociados con posturas políticas de oposición a los gobiernos de la Concertación- produce efectos negativos sobre los niveles de aprobación presidencial. Si bien una lectura es que la información obtenida a través del consumo de medios induce a las personas a fortalecer su ya existente posición política -en este caso una mayor desaprobación al gobierno como resultado de una mala situación económica del país-, una lectura alternativa (consistente con el Modelo Rochester) es que la información que reciben de los medios impresos es la que influiría sobre su menor aprobación presidencial.

Este artículo muestra evidencia que el consumo de medios tiene un efecto sobre la percepción política de las personas. El mayor consumo de medios, en especial de diarios, está relacionado con niveles de aprobación más bajos y niveles de desaprobación más 
altos. Ya sea porque están reforzando predisposiciones políticas iniciales o porque los medios impresos entregan información que refleja las posturas de oposición de sus líneas editoriales, los chilenos que más consumen medios eran también los más pesimistas sobre el desempeño presidencial en 2007 y 2008.

\section{REFERENCIAS}

Anderson, Christopher. 1995. Blaming the Government: Citizens and the Economy in Five European Democracies. Armonk, NY: M. E. Sharpe.

Angell, Alan. 2003. "Party Change in Chile in Comparative Perspective". Revista de Ciencia Política 23 (2): 88-108.

Arriagada, Arturo, Patricio Navia y Martín Schuster. 2010. “Creer Para Ver o Ver Para Creer. Consumo de Medios y Aprobación Presidencial en Chile". Observatorio (OBS*) Journal 4 (1): 349-377.

Asociación Nacional de la Prensa. 2008. Informe SVCL Segundo Semestre 2007. Santiago: Asociación Nacional de la Prensa.

Bargsted, Matías. 2009. La formación de la opinión pública: el rol de la información y las disposiciones políticas de los chilenos. En R. Cordero, (Ed.) La Sociedad de la Opinión. Santiago: Ediciones Universidad Diego Portales, 59-197.

Bresnahan, Rosalind. 2003. "The Media and the Neoliberal Transition in Chile". Latin American Perspectives 133 (30.6) (November): 39-68.

Brody, Richard. 1991. Assessing the President: The Media, Elite Opinion and Public Support. Stanford, CA: Stanford University Press.

Campbell, Angus, Phillip Converse, Warren Miller, Donald Stokes. 1960. The American Voter. New York: John Willey.

Cerda, Rodrigo y Rodrigo Vergara. 2007. "Business cycle and political election outcomes: Evidence from the Chilean democracy". Public Choice 132 (1): 125-36.

Consejo Nacional de Televisión. 1999. Encuesta Nacional de Televisión 1999. Principales Resultados. Santiago: Consejo Nacional de Televisión.

Consejo Nacional de Televisión. 2005. Encuesta Nacional de Televisión 2005. Principales Resultados. Santiago: Consejo Nacional de Televisión.

Consejo Nacional de Televisión. 2008. Encuesta Nacional de Televisión 2008. Principales Resultados. Santiago: Consejo Nacional de Televisión.

Cordero, Rodrigo y Cristobal Marín. 2009. "Medios Masivos, Opinión Pública y Transformación de la Democracia". En Rodrigo Cordero (Ed.), La Sociedad de la Opinión. Santiago: Ediciones Universidad Diego Portales, 251-279.

Cordero, Rodrigo y Cristobal Marín. 2006. Los medios masivos y las transformaciones de la esfera pública. Documentos de Trabajo ICSO-UDP, 7. Santiago.

Crewe, Ivor. 1995. "Voters, parties and leaders thirty years on: western electoral studies and the new democracies of Eastern Europe" en I. Budge y D. McCay (eds.) Developing Democracy. London: Sage, 53-78.

Dermota, Ken. 2002. Chile Inédito. El periodismo bajo democracia. Santiago: Ediciones B.

Dussaillant, Patricio. 2005. Medios y elecciones: La elección presidencial de 1999. Santiago, Chile: Centro de Estudios Bicentenario/CIMAS.

Duch, Raymond M. 2001. "A Developmental Model of Heterogeneous Economic Voting in New Democracies", American Political Science Review 95 (4): 895-910.

Duch, Raymond y Randy Stevenson. 2005. "Context and the Economic Vote: A Multilevel Analysis" Political Analysis 13 (4): 387-409.

Echegaray, Fabián Antonio. 1996. The determinants of electoral choice in Latin America, 1982-1995, Political Science, University of Connecticut. 
Fiorina, Morris. 1978. "Economic Retrospective Voting in American National Elections: a Micro-analysis". American Journal of Political Science 22 (2): 426-43.

Fiorina, Morris. 1981. Retrospective Voting in American National Elections, New Haven, CT: Yale University Press.

Flowers, Julianne, Audrey Haynes y Michael Crespin. 2003. "The Media, the campaign and the message". American Journal of Political Science 47 (2): 259-273.

Garretón, Manuel. 1989. The Chilean Political Process. Boston: Unwin Hyman.

Ghanem, Salma. 1997. "Filling in the Tapestry: The Second Level of Agenda-Setting" in M. McCombs, D.L. Shaw y D. Weaver, eds. Communication and Democracy, New Jersey: Lawrence Erlbaum, 3-14.

Gil, Federico. 1969. El sistema político de Chile. Santiago: Editorial Andrés Bello.

Graber, Doris. 2000. Media Power in Politics. Washington: CQ Press.

Graber, Doris. 2001. Mass Media and American Politics. Washington: CQ Press.

Hellwig, Timothy. 2001. "Interdependence Government Constraints and Economic Voting". The Journal of Politics 63: 1.141-1.162.

Holbrook, Thomas y James C. Garand. 1996. "Homoeconomus? Economic Information and Economic Voting". Political Research Quarterly 49: 351-75.

Iyengar, Shanto, Steve Ansolabehere y Roy Behr. 1992. The Media Game: American Politics in the Age of Television. New York: MacMillan.

Iyengar, Shanto y Jennifer McGrady. 2007. Media politics: a Citizen's Guide. New York: W.W Norton.

Iyengar, Shanto y W. Lance Bennett. 2008. "A New Era of Minimal Effects? The Changing Foundations of Political Communication". Journal of Communication 58 (4): 597-789.

Jamieson, Kathleen Hall. 1996. Packaging the Presidency. A History and Criticism of Presidential Campaign Advertising. Third edition. New York: Oxford University Press.

Jamieson, Kathleen Hall y Karlyn Kohrs Campbell. 2000. The Interplay of Influence: News, Advertising, Politics, and the Mass Media. Belmont, CA: Wadsworth Pub Co.

Jennings, M. Kent y Richard Niemi. 1968. "The Transmission of Political Values from Parents to Child". American Political Science Review 62 (1): 169-184.

Katz, Elihu, Hadassah Haas, Michael Gurevitch. 1973. "On the Use of the Mass Media for Important Things". American Sociological Review 38 (2): 164-181.

Kiewiet D. Roderick. 1983. Macroeconomics and Micropolitics: The Electoral Effects of Economic Issues. Chicago: Univ. Chicago Press.

Kinder, Donald y Roderick Kiewiet. 1981. "Sociotropic Politics: The American Case". British Journal of Political Science 11: 129-161.

Kramer, Gerald H. 1983. “The Ecological Fallacy Revisited: Aggregate- versus Individual-level Findings on Economics and Elections, and Sociotropic Voting". American Political Science Review 77 (1): 92-111.

Lau, Richard y David. P. Redlawsk. 2006. How Voters Decide. Information Processing During Elections Campaigns. New York, Cambridge University Press.

Lazarsfeld, Paul, Bernard Berelson y Hazel Gaudet. 1944. The People's Choice. New York: Columbia University Press.

Lewis-Beck, Michael. 1988. Economics and Elections: The Major Western Democracies. Ann Arbor: Univ. Michigan Press.

Lewis-Beck, Michael y Mary Stegmaier. 2000. "Economic determinants of electoral outcomes". Annual Review of Political Science 3: 183-219.

Lewis-Beck, Michael y Mary Stegmaier. 2007. Economic Models of Voting. The Oxford Handbook of Political Behavior. Russell J. Dalton and Hans-Dieter Klingemann. New York, Oxford University Press, 518-537.

Lewis-Beck, Michael y Martin Paldman. 2000. "Economic voting. An Introduction", Electoral Studies 19: 113-121.

Lipset, Martin y Stein Rokkan. 1990. "Cleavage Structures, Party Systems and Voter Alignments" en Peter Meir (ed.) The West European Party System. New York, Oxford University Press, 91-111. 
Lipset, Martin y Stein. Rokkan. 1967. Cleavage structures, party systems and voter alignments: An introduction. New York, Free Press.

López, Miguel Ángel y Mauricio Morales. 2005. “La capacidad explicativa de los determinantes familiares en las preferencias electorales de los chilenos". Revista Política 45: 87-108.

Markus, Gregory G. 1992. "The Impact of Personal and National Economic Conditions on Presidential Voting, 1956-1988". American Journal of Political Science 36 (3): 829-834.

McCombs, Maxwell. 2004. Setting the agenda: The mass media and public opinion. Cambridge, UK: Polity Press.

McCombs, Maxwell y Donald L. Shaw. 1972. "The Agenda-Setting Function of Mass Media". Public Opinion Quarterly 36 (2): 176-187.

Mishler, William y Richard Rose. 1994. "Support for Parliaments and Regimes in the Transition toward Democracy in Post-Communist Europe". Legislative Studies Quarterly 191 (1): 5-32.

Morales, Mauricio. 2008. “La primera mujer presidenta de Chile. ¿Qué explicó el triunfo de Michelle Bachelet en las elecciones de 2005-2006?". Latin American Research Review 43 (1): 7-32.

Morales, Mauricio y Patricio Navia. 2008. “Aprobación al gobierno y a Michelle Bachelet ¿Dónde está la diferencia?". En Encuesta Nacional UDP. Tercera Versión, ed. Universidad Diego Portales. Santiago: Universidad Diego Portales.

Morales, Mauricio, Patricio Navia y Antonio Poveda. 2008. “Desafección política: ¿Qué tan distintos son los 'ninguno' del resto de la población?". En Encuesta Nacional UDP. Tercera Versión, ed. Universidad Diego Portales. Santiago: Universidad Diego Portales.

Morales, Mauricio y Antonio Poveda. 2007. "El PDC: bases electorales, determinantes de adhesión e impacto en las votaciones de R. Lagos y M. Bachelet". Estudios Públicos 107 (Invierno): 129-65.

Navia, Patricio. 2000. “¿De qué trata una política comunicacional exitosa?". Perspectivas 4 (1): 121-139.

Nannestad, Peter y Martin Paldman. 1994. "The VP-function: A survey of the literature on vote and popularity functions after 25 years". Public Choice 79 (3-4): 213-245.

Norpoth, Helmut. 1996. "Presidents and the Prospective Voter". The Journal of Politics 58: 776-92.

Norris, Pippa. 2003. A Virtuous Circle. Cambridge: Cambridge University Press.

Pacek, Alexander y Radcliff Benjamin. 1995. "Economic Voting and the Welfare State: a Cross-National Analysis". The Journal of Politics 57: 44-61.

Popkin, Samuel. 1991. The Reasoning Voter. Chicago: The University of Chicago Press.

Popkin, Samuel. 1995. "Information Shortcuts and the Reasoning Voter", en Groffman, Bernard (coord.), Information, Participation and Choice: An Economic Theory of Democracy in Perspective, Ann Arbor: University of Michigan Press, 17-35.

Powell, G. Bingham Jr. y Guy D. Whitten (1993). "A Cross-National Analysis of Economic Voting: Taking Account of the Political Context". American Journal of Political Science 37 (2): 391-414.

Przeworski, Adam. 1991. Democracy and Market: Political and Economic Reform in Eastern Europe and Latin America. New York: Cambridge University Press.

Radcliff, Benjamin. 1988. "Solving a Puzzle: Aggregate Analysis and Economic Voting Revisited". The Journal of Politics 50 (2): 440-455.

Rudolph, Thomas y J. Tobin Grant. 2002. “An Attributional Model of Economic Voting: Evidence from the 2000 Presidential Election". Political Research Quarterly 55 (4): 805-823.

Scully, Timothy R. 1992. Rethinking the Center. Party Politics in Nineteenth- and Twentieth-Century Chile. Stanford: Stanford University Press.

Suzuki, Motoshi y Henry W. Chappel, Jr. 1996. "The Rationality of Economic Voting Revisited". The Journal of Politics 58 (1): 224-236.

Tironi, Eugenio y Guillermo Sunkel. 1993. “Modernización de las comunicaciones y democratización de la política. Los medios en la transición a la democracia en Chile". Estudios Públicos 52: 215-256.

Universidad Diego Portales. 2007. Tercera Encuesta Nacional UDP. Santiago. Disponible en www.icso.cl

Valenzuela, Arturo y J. Samuel Valenzuela, eds. 1976. Chile: Politics and Society. New Brunswick: Transaction Books. 
Valenzuela, J. Samuel y Timothy R. Scully. 1997. “Electoral choices and the party system in Chile-Continuities and changes at the recovery of democracy". Comparative Politics 29 (4): 511-27.

Valenzuela, Sebastián y Teresa Correa. 2006. "Prensa y candidatos presidenciales 2005: Así los mostramos, así los miraron". Cuadernos de Información UC 19: 89-96.

Ventura, Raphael. 2001. "Family Political Socialization in Multiparty Systems". Comparative Political Studies 4 (6): 666-691.

Weaver, David H, Doris Graber, Maxwell McCombs y Chaim H. Eyal. 1981. Media agenda setting in a presidential election: Issues, images and interest. Westport, CT: Greenwood.

World Internet Project (WIP). 2006. Monitoreando el futuro digital: resultados encuesta WIP-Chile 2006. Noviembre, 2006. Santiago. Disponible en: www.wipchile.cl

Zaller, John. 1991. "Information, Values and Opinion". American Political Science Review 85 (4): 12151237.

Zaller, John. 1992. The Nature and Origins of Mass Opinion. New York: Cambridge University Press.

Arturo Arriagada Ilabaca es Instructor en la Universidad Diego Portales y actualmente realiza estudios de Doctorado en Sociología en London School of Economics.

arturo.arriagada@udp.cl

Patricio Navia Lucero es Master Teacher of Global Studies en New York University y profesor asociado de ciencia política en la Universidad Diego Portales.

patricio.navia@udp.cl

Martín Schuster Pineda es Licenciado en ciencia política de la Universidad Diego Portales. Investigador asociado del Observatorio Electoral del ICSO-UDP.

martin.schuster@gmail.com 
